\title{
Is the knowledge of the surface topology and contact angles enough to define the drop impact outcome?
}

\author{
Ileana Malavasi, ${ }^{1}$ Federico Veronesi, ${ }^{2}$ Aurora Caldarelli, ${ }^{2}$ Maurizio Zani, ${ }^{3,4}$ Mariarosa Raimondo, ${ }^{2}$ \\ Marco Marengo ${ }^{1,5^{*}}$
}

${ }^{1}$ Department of Engineering and Applied Sciences, University of Bergamo, Viale Marconi 5, 24044 Dalmine (BG), Italy.

${ }^{2}$ ISTEC CNR - Institute of Science and Technology for Ceramics, Via Granarolo 64, 48018 Faenza (RA), Italy.

3 Department of Physics, Politecnico di Milano, Piazza Leonardo da Vinci 32, 20133 Milano, Italy.

${ }^{4}$ Center for Nano Science and Technology @Polimi, Istituto Italiano di Tecnologia (IIT), Via G. Pascoli 7o/3, 20133

Milano, Italy.

${ }^{5}$ School of Computing, Engineering and Mathematics, University of Brighton, Lewes Road, BN2 4GJ, Brighton, UK.

\begin{abstract}
It is well known that a superhydrophobic surface may not be able to repel impacting droplets due to the socalled Cassie-to-Wenzel transition. It has been proven that a critical value of the receding contact angle $\left(\theta_{R}\right)$ exists for the complete rebound of water, recently experimentally measured to be $100^{\circ}$ for a large range of impact velocities. On the contrary, in the present work, no rebound was observed when low surface tension liquids such as hexadecane $(\sigma=27.5$ $\mathrm{mN} / \mathrm{m}$ at $25^{\circ} \mathrm{C}$ ) are concerned, even for very low impact velocities and very high values of $\theta_{R}$ and low contact angle hysteresis. Therefore, the critical threshold of $\theta_{R} \approx 100^{\circ}$ does not sound acceptable for all liquids and for all the hydrophobic surfaces. For the same Weber numbers a Cassie-to-Wenzel state transition occurs after the impact due to the easier penetration of low surface tension fluids in the surface structure. Hence a criterion for drop rebound of low surface tension liquids must consider not only the contact angle values with surfaces, but also their surface tension and viscosity. This suggests that, even if it is possible to produce surfaces with an enhanced static repellence against oils and organics, generally the realization of synthetic materials with remaining self-cleaning and anti-sticking abilities in dynamic phenomena, such as spray impact for example, still remains an unsolved task. Moreover, it is demonstrated that also the chemistry of the surface and the physico-chemical interactions with the liquid drops and the possible wettability gradient of the surface asperity play an important role in determining the critical Weber number above which impalement occurs. Therefore the classical numerical simulations of drop impacts onto dry surfaces are definitively not able to capture the final outcomes of the impact for all the possible fluids, if the surface topology and chemistry and/or the wettability gradient in the surface structure are not properly reflected.
\end{abstract}

\section{INTRODUCTION}

The impact of drops onto dry solid surfaces is a phenom- 19 enon involved in many industrial applications, i.e. spray 20 cooling, ink-jet printing, spray painting, fuel injection, 21 raindrop erosion, etc. The investigation of the single drop 22 impact ${ }^{1-3}$ is the first step toward the understanding and 23 the control of the liquid-solid interactions in complex 24 phenomena where the capillarity, the viscous forces and 25 the impact momentum play a key role. In the last decade, 26 notwithstanding the open issue of their durability ${ }^{4}$, su- 27 perhydrophobic surfaces (SHS) have attracted an increas- 28 ing interest in both the academic and industrial sectors, 29 due to their remarkable self-cleaning and anti-sticking 30 properties $^{5-7}$, involving a wide range of potential applica- 31 tions: biomedical ${ }^{8-9}$, microfluidic ${ }^{10}$, corrosion resistance ${ }^{11}, 32$ drag reduction $^{12}$, anti-icing ${ }^{13}$, contamination and oxidation 33 protection $^{14}$, etc. SHS are highly hydrophobic surfaces on 34 which liquid water adhesion is very low, therefore resulting extremely difficult to be wetted. Superhydrophobicity causes the water droplet to bead up on the surface instead of spreading on it. In addition, capillary adhesion forces are low and water drops typically preserve a high mobility on the surface. The wetting behavior is evaluated by the contact angle occurring when a liquid/vapor interface meets the solid surface. In this work, advancing $\left(\theta_{\mathrm{A}}\right.$ or ACA) and receding ( $\theta_{R}$ or RCA) contact angles were measured, respectively, by expanding and contracting water and hexadecane sessile drops on a horizontal surface (sessile drop method). In static conditions, $\theta_{\mathrm{A}}$ and $\theta_{\mathrm{R}}$ are, respectively, the maximum and the minimum stable angles. Both of them provide the range of contact angles at equilibrium, while their difference $\Delta \theta=\theta_{A}-\theta_{R}$ - named as contact angle hysteresis (CAH) - provides an indication of the drop mobility (the lowest the $\Delta \theta$ value, the highest the drop mobility). As reported in the literature, the 
standard conditions are $\theta_{R}>135^{\circ}$ and $\Delta \theta<10^{\circ}$ for superhy- 90 drophobicity ${ }^{4}, \theta_{A}>90^{\circ}$ for hydrophobicity and $\theta_{A}<90^{\circ}$ for 91 hydrophilicity ${ }^{15}$. A surface able to repel liquids with a dif- 92 ferent polarity and physical properties (i.e. surface ten- 93 sion) is called amphiphobic or lyophobicic-20, with both 93 terms being usually related to the liquids molecules and 94 not to the surfaces. Such particular non-wetting surfaces 95 can provide additional performances with respect to the 96 hydrophobic ones in many sectors. Similarly, superam- 97 phiphobic surfaces exhibit even larger values of static 98 contact angles and $\mathrm{CAH}$ lower than $5^{\circ}$. Different ap- 99 proaches can be used to achieve these surface properties 100 For recent trends in the development, fabrication, and 101 characterization of superamphiphobic surfaces, the pa 102 pers of Cavalli and Mugele ${ }^{16}$, Chua and Seeger ${ }^{20}$ give use 103 ful insights. Throughout the impact on such surfaces, the $\mathrm{e}^{104}$ drop mobility is related to a sort of "dynamic superam 105 phiphobicity", defined as the critical wetting value unde106 which an impacting drop with a given impact velocity 107 does not wet the surface, i.e. a complete drop rebound is 108 observed. In this case the impact velocity, the interfacia109 tension, the viscosity of the liquid, the chemical and phys 110 ical properties of the surface determine the drop outcome $\mathrm{e}^{111}$ as well as the spreading and the retraction dynamic 112 Nonetheless, a few papers ${ }^{21-23}$ have shown how superam 113 phiphobic surfaces might not necessarily lead to a tota 114 rebound of impinging water drops, especially above a giv 115 en value of Weber number $\left(\mathrm{We}=\rho \mathrm{v}^{2} \mathrm{D}_{\mathrm{o}} / \sigma\right.$, where $\rho$ is the ${ }^{116}$ density of the fluid $\left[\mathrm{kg} / \mathrm{m}^{3}\right], \mathrm{v}$ is its impact velocity $[\mathrm{m} / \mathrm{s}], 117$ $D_{o}$ is the droplet diameter $[\mathrm{m}]$ and $\sigma$ is the surface tension 118 $[\mathrm{N} / \mathrm{m}]$ ). Eventually impalement can occur, leading to the 119 droplet deposition on the surface. In this sense a surface 120 only hydrophobic, but smoother or with a proper topolo-121 gy can be more effective in repelling liquids even for a122 large value of We. Recently Antonini et al. ${ }^{21}$ analyzed the 23 drop impact on horizontal surfaces and highlighted the124 role of the $\theta_{R}$ on the drop rebound. Accordingly, the re 125 bound can be observed only on surfaces presenting $\theta_{1} 26$ greater than $100^{\circ}$ with the rebound time decreasing as $\theta_{\text {凡 } 27}$ increases. However, Antonini et al. only refer to water as 128 impacting liquid ${ }^{21}$.

To better understand the existence of a general criterion130 to predict the drop impact outcome, and the key parame-131 ters governing the drop-surface interaction, the normall 32 impact of both water and hexadecane drops on solid dry133 surfaces with different wettability was observed using a134 high-speed camera. The wetting behavior of sandblasted 35 aluminum foils before (TQ sample) and after the deposi-136 tion of: i) organic-inorganic hybrid coatings (S samples),137 ii) infused hybrid coatings (SI samples), iii) grafting fatty138 acid treatments (LAU) and iv) grafting FAS (FAS) ha\$39 been analyzed. The present study aims at establishing $\mathbb{1} 40$ relationship between drop impact outcomes and the dif 141 ferent parameters for both the liquid drop (impact veloci-142 ty, surface tension, viscosity) and the solid surface (morphology and roughness, chemistry, wettability).

\section{EXPERIMENTAL SECTION}

Surface fabrication - Four kinds of SHS have been prepared: S, SI, LAU and FAS. Moreover, the uncoated sandblasted aluminum surface taken as reference is named TQ. S samples were prepared by dip-coating aluminum foils in an aqueous alumina sol with average particle size of about $30 \mathrm{~nm}$. After thermal treatments, also including boiling in deionized water, a nanostructured inorganic coating was obtained, which was then further functionalized by dipping in a commercial solution of fluoroalkylsilane in isopropanol (Dynasylan ${ }^{\circledast}$ SIVO CLEAR EC, Evonik), resulting into a hybrid organic-inorganic coating. More details on the fabrication of S samples were reported by Raimondo et al. in a previous work ${ }^{24}$. SI samples were obtained by the same route, with an additional step of immersion into a fluorinated lubricant (Fluorinert ${ }^{\mathrm{TM}}$ FC $-43,3 \mathrm{M}^{\mathrm{TM}}$ ) allowing for the formation of a continuous liquid film on the material surface with the aim of changing the physical nature of the interface (from the solidliquid-air of S samples to the liquid-liquid-air of SI ones, according to the so-called SLIPS approach ${ }^{25-26}$ ). Fatty acid surfaces (LAU) were fabricated on an aluminum substrate, previously etched in acid solution, to achieve the desired surface roughness, and subsequently grafted in an ethanol lauric acid solution 4 . FAS surfaces were fabricated by etching the surface in acid solution as for the LAU surface, and then functionalized in a water solution of perfluoroctyltriethoxysilane (FAS) ${ }^{27}$.

Surface characterization - The average values of $\theta_{A}, \theta_{R}$ and $\mathrm{CAH}$ with both water and hexadecane are reported in Figure 1 . The contact angle $\theta$ was calculated automatically from drop images by measuring the tangent of a circle fitting the drop profile at the contact point (OCA 15, Data Physics Instr.). Typical drop volume was about $2 \mu$ l.

Surfaces have also been characterized in terms of topography and roughness. SEM images were obtained with a Tescan MIRA3 equipment, while roughness measurements were performed with a ContourGT-K (Bruker Nano $\mathrm{GmbH}$ ) optical profilometer (vertical resolution < 0.01 $\mathrm{nm}$, lateral resolution $0.38 \mu \mathrm{m}$ ). SEM images of S and SI surfaces (Figure 2) show a flower-like nanostructure made up of crossed, $200 \mathrm{~nm}$ long flakes and nanometric cavities. Previous results ${ }^{24}$ proved that such structure is due to the $\gamma$-alumina coating obtained by deposition of $\mathrm{Al}_{2} \mathrm{O}_{3}$ nanoparticles and to the subsequent boiling in water. LAU and FAS samples display a terrace-like structure with sub-micrometric edges, as expected from the similar etching conditions held for both samples. On the sandblasted TQ surface taken as a reference, microabrasion by sand grains produced an irregular microstructure with asperities and cavities. Roughness data $\left(\mathrm{S}_{\mathrm{a}}, \mathrm{S}_{\mathrm{q}}, \mathrm{S}_{\mathrm{v}} \text { and } \mathrm{S}_{\mathrm{z}}\right)^{28}$ are 
shown in Figure 3. $\mathrm{S}_{\mathrm{a}}$ defines the average of the absolutel 54 values of the profile heights $\mathrm{Z}(\mathrm{x}, \mathrm{y})$ in the measured area,155 while $S_{q}$ is the root mean squared of $Z(x, y)$ in the meas 156 ured area. $S_{v}$ expresses the maximum value of "valley"157 depth on the surface in the measured area and $\mathrm{S}_{\mathrm{z}}$ express 158 es the sum of the maximum value of peak height and the159 maximum value of valley depth on the surface within the160 measured area. A $15 \times 15 \mathrm{~mm}^{2}$ area was analyzed for every 161 measure, and a minimum of three measurements werel62 done on the same sample for repeatability reason. The163 difference between coated (S, SI) and etched (LAU, FAS) samples can be remarked: the former have lower average roughness $\left(\mathrm{S}_{\mathrm{a}}, \mathrm{S}_{\mathrm{q}}\right)$ but higher peaks $\left(\mathrm{S}_{\mathrm{v}}, \mathrm{S}_{\mathrm{z}}\right)$. A comparison with the data obtained for a TQ surface led us to conclude that the hybrid nanostructured coating has a small influence on the micrometric roughness of S and SI, while the main contribution belongs to the microstructure provided by sandblasting. On LAU and FAS surfaces, etching provided a rougher structure, but with less pronounced asperities and cavities.
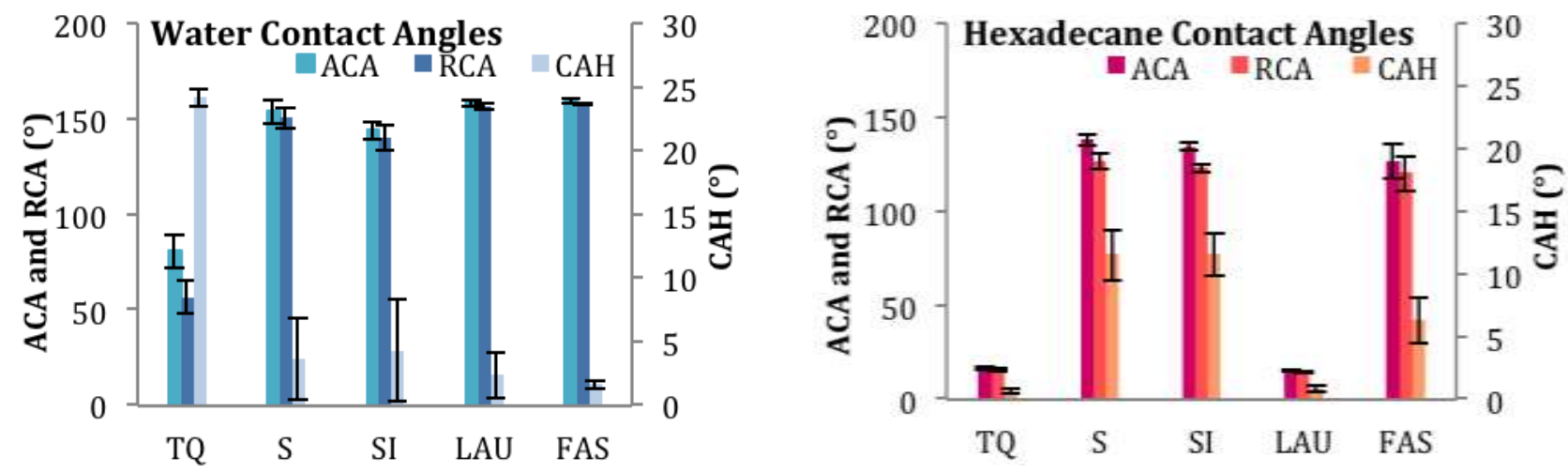

Figure 1. Average advancing (ACA) and receding contact angles (RCA) and contact angle hysteresis (CAH) with water (left) and hexadecane (right).

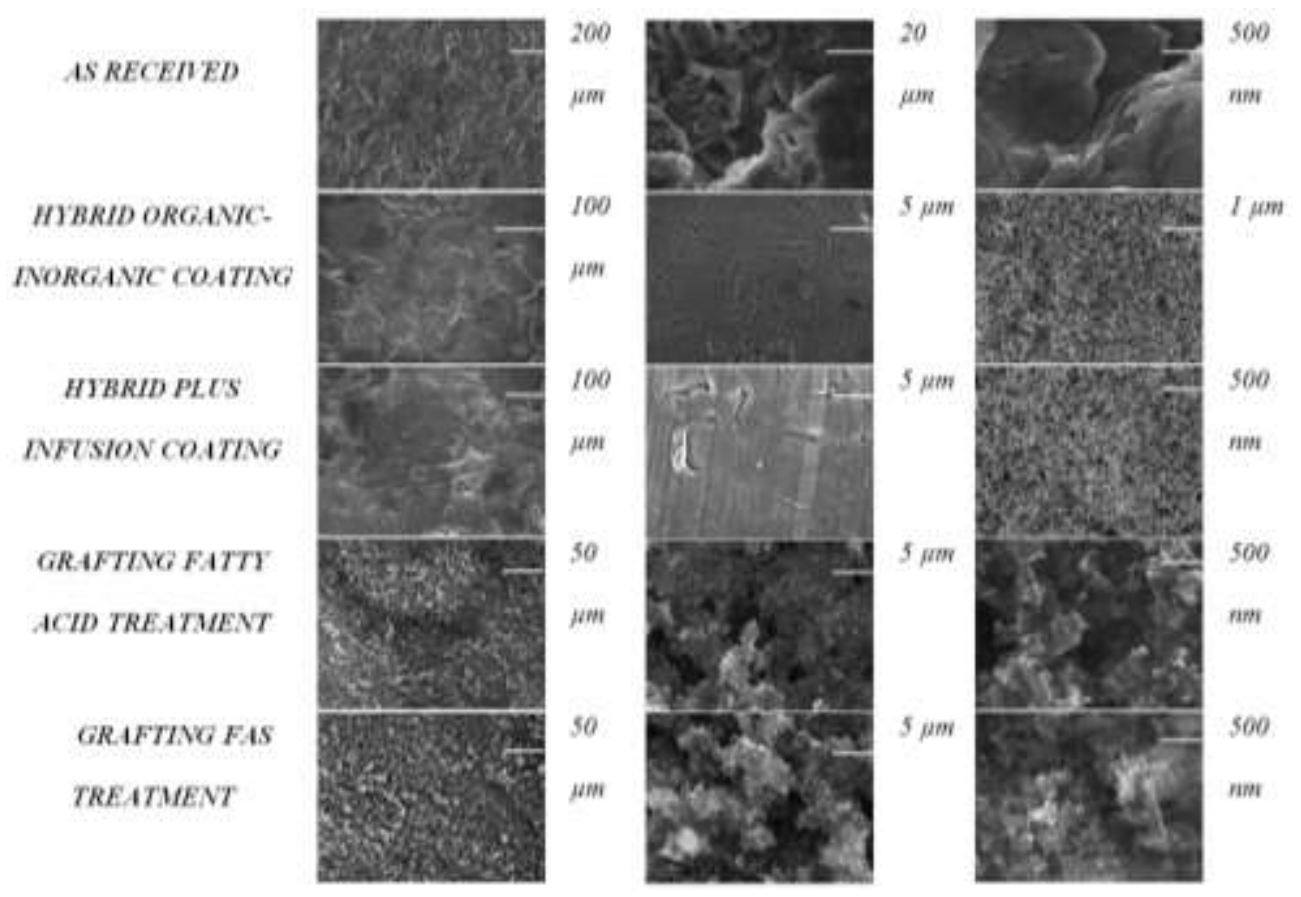

Figure 2. SEM images of the sample surfaces: as received sandblasted (TQ), hybrid organic-inorganic coating (S), hybrid plus infusion coating (SI), grafting fatty acid treatment (LAU) and grafting FAS treatment (FAS). 


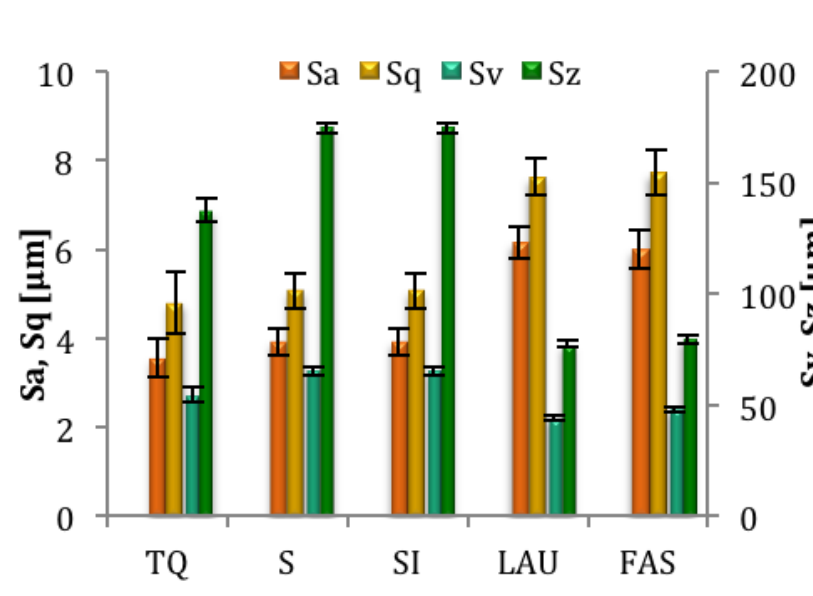

2 Figure 3. Surface roughness data obtained on TQ, S, SI,

3 LAU and FAS samples. $S_{a}$ and $S_{q}$ values are referred to the

4 left vertical axis, while $S_{v}$ and $S_{z}$ are referred to the right

5 vertical axis.

6 Drop impact experiments - A typical experimental ap- 42 7 paratus for drop impact studies was used: a drop was gen-

8 erated at the tip of a hydrophobic needle, and then was

9 accelerated by gravity and impacted onto a dry, solid sur-

10 face. Experimental conditions were the following: impact

speed in the $0.05<\mathrm{V}<4.2 \mathrm{~m} / \mathrm{s}$ range, drop diameter in the 47 $1.5<\mathrm{D}_{\mathrm{o}}<2.6 \mathrm{~mm}$ range, Weber numbers in the $0.1<\mathrm{We}<48$ 635 range, and Ohnesorge number $\left(\mathrm{Oh}=\mu /\left(\rho \sigma \mathrm{D}_{\mathrm{o}}\right)^{1 / 2}, 49\right.$ where $\mu$ is the liquid viscosity [Pa s]) in the $0.0023<\mathrm{Oh}<50$ o.o186 range. Images of drop impacts were recorded using 51 a high-speed camera (PCO 1200-HS) with typical frame 52 rates of 1568 and $2477 \mathrm{fps}$ and a pixel resolution of ${ }_{31} 53$ $\mu \mathrm{m} /$ pixel. Tests were repeated at least 10 times for each 54 condition to assess experimental reproducibility. Images 55

were manually analyzed to identify the drop impact out-

come and eventually to measure the time of the drop re-

bound when occurring.

\section{RESULTS AND DISCUSSION}

25 In Table 1 and in Figure 4 the summary of all the out26 comes of the drop impact tests is reported. Five main re27 gimes stand out: complete rebound, partial rebound, prompt splash, receding breakup and deposition. All the functionalized surfaces are able to generate a complete or partial rebound of water drops, while TQ surface promotes drop deposition for We up to about 200 and reced2 ing break-up for higher Weber numbers. Remarkably, 33 surfaces $\mathrm{S}$ and SI are able to repel the water drops up to 34 the maximum We value of 620. No splash is observed for 35 the entire range of We, confirming the previous literature results $^{29}$. In the case of hexadecane, no rebound was observed for any of the surfaces, even if the contact angles and the hysteresis reached, respectively, very high and very low values (i.e. FAS surface, see Figure 1). The prompt splash appears to be an important outcome for We $>$ 200. FAS sample shows a peculiar behavior, since it produces a partial rebound with water even for moderate values of We, while with hexadecane it is able to allow the generation of a singular jet $3^{30}$ for very low $\mathrm{We}$, and allows the receding breakup behavior for the higher analyzed We. Image sequences of water and hexadecane liquid drops normally impacting on the tested surfaces are shown in Figures 5 and 6, respectively. Interestingly, when a water drop impacts on TQ at We $\approx 21$, deposition occurs with the generation of a singular jet ${ }^{30}$, as shown in Figure 7. The same behavior can be observed in the case of hexadecane drop impacting on FAS surface at We $\approx 15$.

A schematic representation of the drop impact test outcome is reported in Figure 4.

Table 1. Summary of the outcomes of the drop impact tests. $\mathrm{R}=$ rebound, $\mathrm{PR}=$ partial rebound, $\mathrm{PS}=$ prompt splash, $\mathrm{RB}=$ receding breakup, $\mathrm{D}=$ deposition. ${ }^{*}$ Singular jet. ${ }^{* *}$ Transition region.

\begin{tabular}{c||c|c|c|c|c|c|c||c|c|c|c|c|c|c||}
\multicolumn{1}{c||}{} & \multicolumn{10}{c||}{ We (WATER) } \\
\cline { 2 - 14 } $\begin{array}{c}\text { Surface } \\
\text { type }\end{array}$ & $<$ & 16 & 40 & 65 & 150 & 270 & 500 & 10 & 30 & 60 & 85 & 205 & 325 & 545 \\
\hline $\mathrm{TQ}$ & $\mathrm{D}$ & $\mathrm{D}^{*}$ & $\mathrm{D}$ & $\mathrm{D}$ & $\mathrm{D}$ & $\mathrm{RB}$ & $\mathrm{RB}$ & $\mathrm{D}$ & $\mathrm{D}$ & $\mathrm{D}$ & $\mathrm{D}$ & $\mathrm{D}$ & $\mathrm{PS}$ & $\mathrm{PS}$ \\
$\mathrm{S}$ & $\mathrm{R}$ & $\mathrm{R}$ & $\mathrm{R}$ & $\mathrm{R}$ & $\mathrm{R}$ & $\mathrm{R}$ & $\mathrm{R}$ & $\mathrm{D}$ & $\mathrm{D}$ & $\mathrm{D}$ & $\mathrm{D}$ & $\mathrm{PS}$ & $\mathrm{PS}$ & $\mathrm{PS}$ \\
$\mathrm{SI}$ & $\mathrm{R}$ & $\mathrm{R}$ & $\mathrm{R}$ & $\mathrm{R}$ & $\mathrm{R}$ & $\mathrm{R}$ & $\mathrm{R}$ & $\mathrm{D}$ & $\mathrm{D}$ & $\mathrm{D}$ & $\mathrm{D}$ & $\mathrm{PS}$ & $\mathrm{PS}$ & $\mathrm{PS}$ \\
$\mathrm{LAU}$ & $\mathrm{R}$ & $\mathrm{R}$ & $\mathrm{R}$ & $\mathrm{R}$ & $\mathrm{R}$ & $\mathrm{R}$ & $\mathrm{PR}$ & $\mathrm{D}$ & $\mathrm{D}$ & $\mathrm{D}$ & $\mathrm{D}$ & $\mathrm{D}$ & $\mathrm{PS}$ & $\mathrm{PS}$ \\
$\mathrm{FAS}$ & $\mathrm{R}$ & $\mathrm{R}$ & $\mathrm{R}$ & $\mathrm{R}$ & $\mathrm{PR} / \mathrm{R}^{* *}$ & $\mathrm{PR}$ & $\mathrm{PR}$ & $\mathrm{D}^{*}$ & $\mathrm{D}$ & $\mathrm{D} / \mathrm{RB}^{* *}$ & $\mathrm{D} / \mathrm{RB}^{* *}$ & $\mathrm{D} / \mathrm{RB}$ & $\mathrm{RB}$ & $\mathrm{RB}$ \\
\hline
\end{tabular}



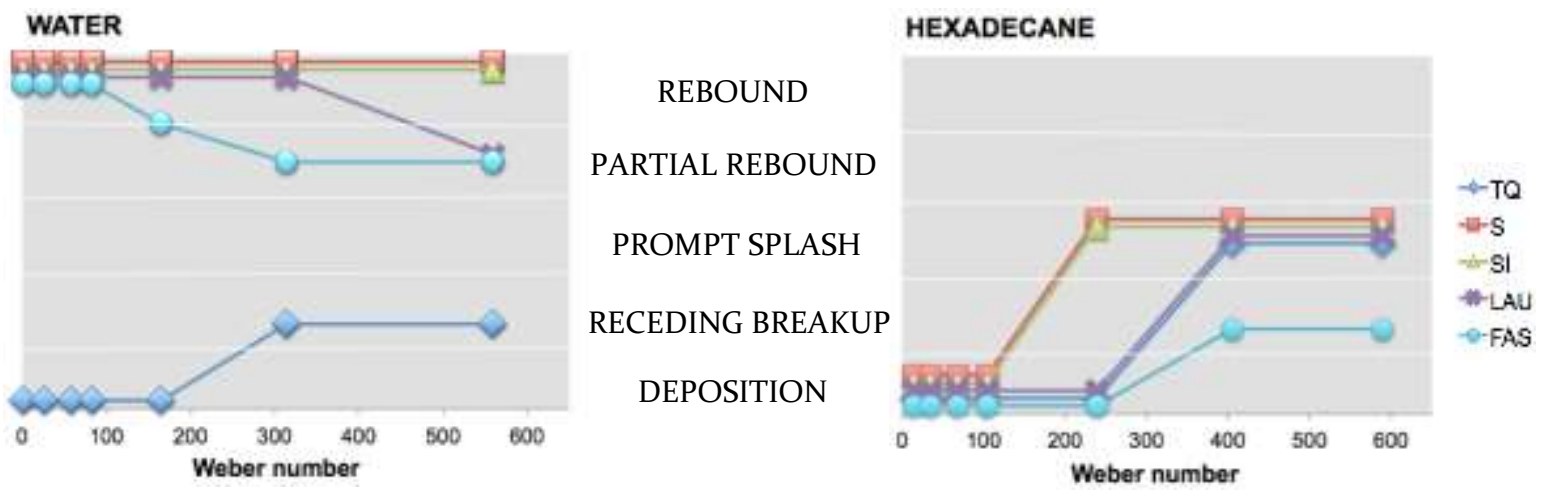

Figure 4. Schematic representation of the drop impact test outcome. In the graphs, the mean values of each We interval are reported.

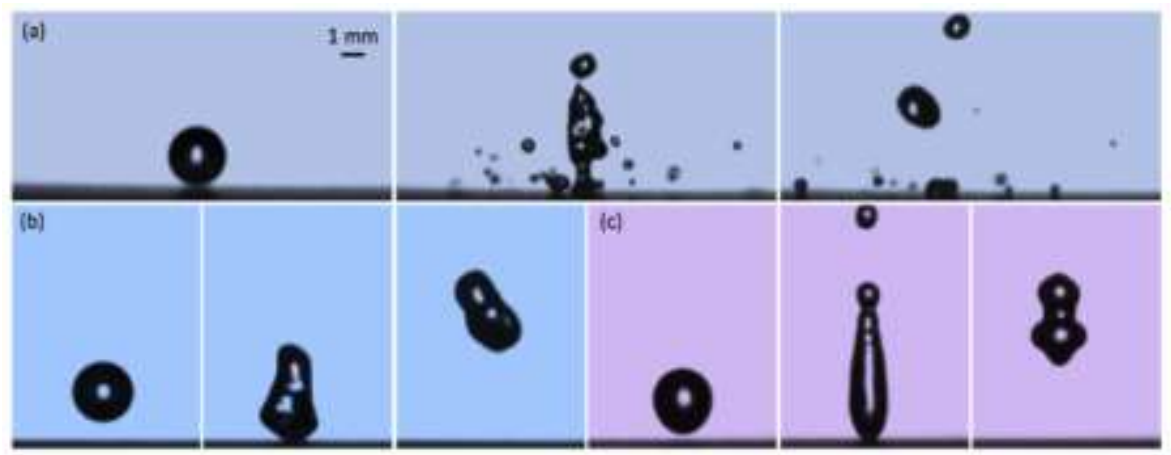

Figure 5. Image sequences of water drops (average diameter $D_{0}=2.45 \mathrm{~mm}$ ) impacting on three functionalized surfaces: (a) partial rebound with fragmentation on FAS sample at $\mathrm{We}=312$ at $\mathrm{t}=0,14.6 \mathrm{~ms}$ and $31.2 \mathrm{~ms}$ after impact; (b) rebound on SI sample at $\mathrm{We}=54$ at $\mathrm{t}=0,11.5 \mathrm{~ms}$ and $31.2 \mathrm{~ms}$ after impact; (c) rebound on $\mathrm{S}$ sample at $\mathrm{We}=21$ at $\mathrm{t}=0,14.0 \mathrm{~ms}$ and 21.6 ms after impact. The scale bar in (a) is valid for all images.
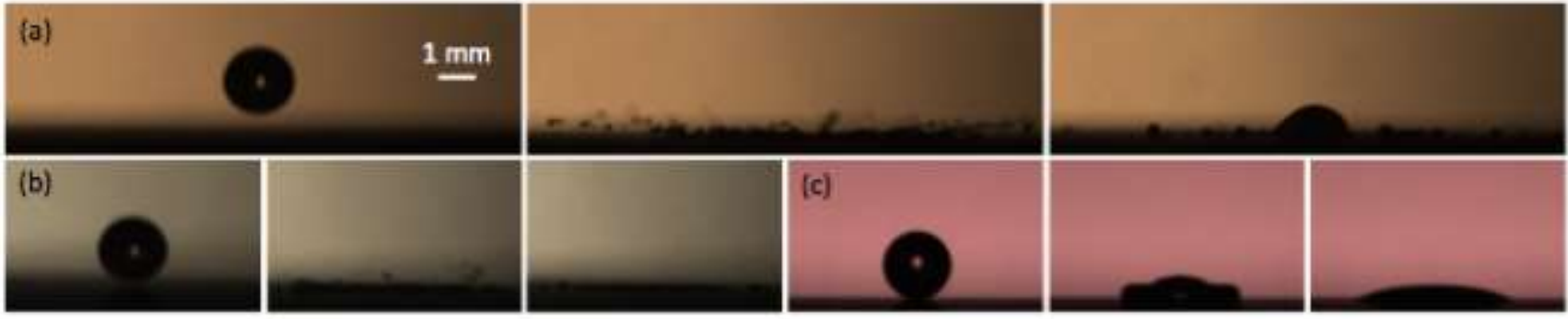

Figure 6. Image sequences of hexadecane drops (average diameter $D_{o}=1.66 \mathrm{~mm}$ ) impacting on three functionalized surfaces displaying different behavior: (a) receding breakup on FAS sample at We $=560$; (b) splash on SI sample at We $=580$; (c) deposition on LAU sample at $\mathrm{We}=17$. For every surface, images at $\mathrm{t}=0,2.0 \mathrm{~ms}$ and $17.6 \mathrm{~ms}$ after impact are reported. The scale bar in (a) is valid for all images.

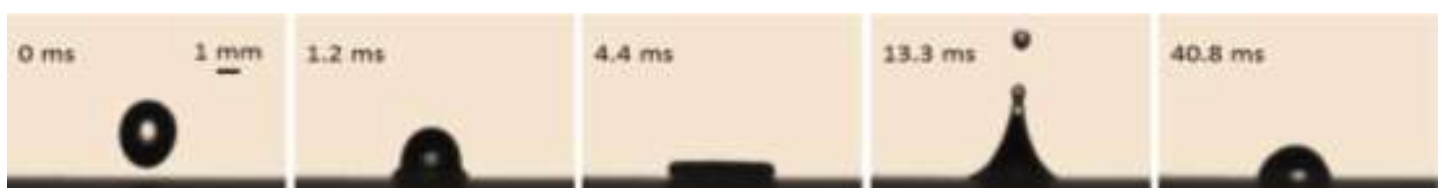

Figure 7. Image sequence of water drop (average diameter $\mathrm{D}_{\mathrm{o}}=2.35 \mathrm{~mm}$ ) impacting on TQ surface at $\mathrm{We}=21$. A deposition occurs with the generation of a secondary drop. The scale bar in the first frame is valid for all images. 
1 The evolution of the spreading film diameter of water and 10

2 hexadecane after the instant of impact is shown in Figures 11

$38 \mathrm{a}$ and $8 \mathrm{~b}$, respectively. The dimensionless diameter of 12

4 the spreading film, called the spread factor, $\xi(t)=D(t) / D_{0} 13$

5 (i.e., the contact diameter at time $t$, made dimensionless 14

6 by dividing it for the initial drop diameter) is shown as 15

7 function of time. Different outcomes were observed from 16

8 deposition to rebound (occurring for $\mathrm{t}>\mathrm{o}$ when $\xi=0$ ). In 17

9 SHS cases, drops do not stick on the surface and the re- 18

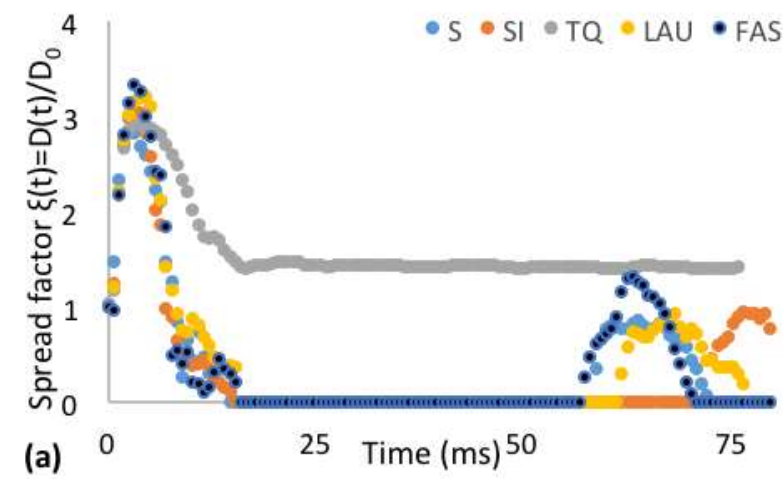

bounds of the droplets can be observed. When the drop is detached from the surface, the contact diameter is zero, therefore the spread factor is zero. The time evolution of the spread factor suggests that the drop impact dynamics depends not only on the $\theta_{R}$ value, since, contrary to what reported by Antonini et al. ${ }^{21}$, even when $\theta_{R}$ reaches $120^{\circ}$ indicating a very low wettability, complete drop rebound does not occur (see tests with hexadecane on FAS surfaces, Figure $8 b$ ).

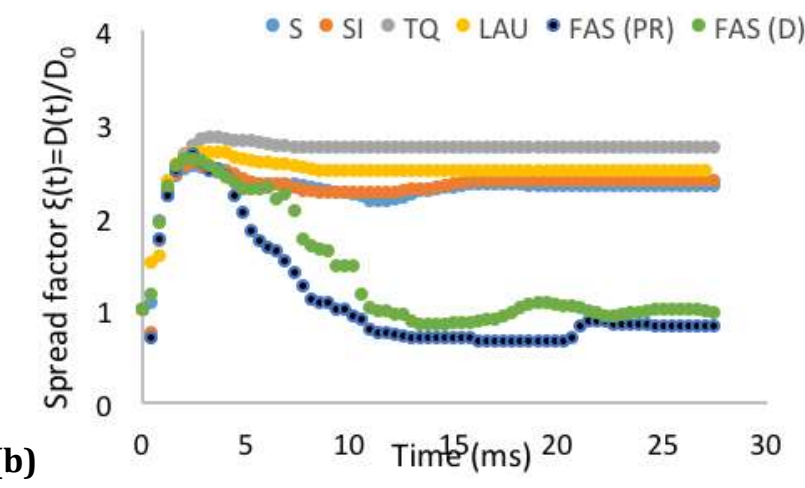

Figure 8. Spread factor time evolution, $\xi(t)=D(t) / D_{0}$, for the tested samples (single runs). (a) Water test conditions: $V=1.6$ $\mathrm{m} / \mathrm{s}, \mathrm{D}_{\mathrm{o}}=2.5 \mathrm{~mm}$, and $\mathrm{We} \approx 90$. (b) Hexadecane test conditions: $\mathrm{V}=1.5 \mathrm{~m} / \mathrm{s}, \mathrm{D}_{\mathrm{o}}=1.7 \mathrm{~mm}$, and $\mathrm{We} \approx 110$.

1 The fact that a surface is superhydrophobic, i.e. with an 30

2 extremely high advancing contact angle and low hystere- 31

3 sis, is not enough to assure the complete rebound, since 32

4 impalement can occur. ${ }^{21}$ Therefore it is interesting to un- 33

5 derstand when the impalement impedes the bouncing 34

6 and which are the possible outcomes of drop impact for 35

7 the different fluid and surface characteristics. The im- 36

8 palement is usually described using alternatively four dif- 37

9 ferent pressure mechanisms, the water hammer pressure 38

$10 \mathrm{P}_{\mathrm{wH}}$, the dynamic spreading pressure $\mathrm{P}_{\mathrm{SD}^{31}}$, the capillary or 39

11 anti-wetting pressure $\mathrm{P}_{\mathrm{C}^{32}}$ and the gas layer pressure $\mathrm{P}_{\mathrm{GL}^{2}}{ }^{22} .40$

12 This last pressure term comes out considering the com- 41

13 pression effects of the gas under the drop rather than the 42

14 liquid compressibility. The initial impact of the droplet 43

15 onto the surfaces generates a water hammer pressure $\mathrm{P}_{\mathrm{wH}} 44$

16 due to the compression of the liquid ${ }^{32-34}$. The water ham- 45 spreading velocity. For a normal impact $\mathrm{P}_{\mathrm{EWH}}$ is supposed to be greater than $\mathrm{P}_{\mathrm{SD}}$. The capillary pressure can be defined as the liquid pressure level that it is necessary to overcome in order to squeeze a droplet through a pore cavity, such as a surface topology throat. For that reason it is also called "anti-wetting" pressure. The capillary pressure can be written as $\mathrm{P}_{\mathrm{C}} \approx \sigma\left(-\cos \theta_{\mathrm{A}}\right) / \mathrm{r}_{\mathrm{p}}$, where $\sigma$ is the surface tension, $\theta_{\mathrm{A}}$ is the advancing contact angle of the corresponding smooth surface and $r_{p}$ is a length scale of the surface cavities. The analysis of droplet impact on textured surfaces showed that the compressibility of the air layer between droplet and the substrate is a key feature for the impalement. Maitra et al. ${ }^{22}$ showed that the meniscus penetration is probably linked to the compressibility of the draining air, rather than the water hammer pressure effect of the liquid. Therefore, instead of the water hammer pressure, using a dimensional analysis they defined a pressure term $\mathrm{P}_{\mathrm{GL}}=0.88\left(\mathrm{R} \mu_{\mathrm{g}}{ }^{-1} \mathrm{U}^{7} \rho_{1}{ }^{4} \mathrm{Ca}\right)^{1 / 3} / \mathrm{St}^{4 / 9}$, where $\mathrm{R}$ is the droplet radius, $\mu_{\mathrm{g}}$ the air viscosity, Ca the Capillary number, and St the Stokes number, as the critical pressure above which Cassie-to-Wenzel Transition occurs.

The impalement can be total, i.e. the liquid is reaching the bottom of the surface when the same is textured with pillars or is completely wetting the surface structure for a random topology, or partial, when the liquid is not able to wet completely and some air is still present in the surface throats and cavities. One can distinguished three regimes, the Wenzel regime where impalement occurs and is pre- 
sent until the final deposition, being the liquid imbibedl14 into the surface structure, a fakir (or Cassie-Baxter) re 115 gime, when no impalement and no imbibition occur forl 16 all the duration of the drop impact, from the early stages 17 until the possible rebound or deposition, and a thirdl 18 stage, called partially impaled state, when a partial im 119 palement is present. In the case $\mathrm{P}_{\mathrm{C}}>\mathrm{P}_{\mathrm{EWH}}>\mathrm{P}_{\mathrm{SD}}$, the surfacel 20 textured structure resists wetting in the contact and in121 the spreading phase; in the case $\mathrm{P}_{\mathrm{EWH}}>\mathrm{P}_{\mathrm{C}}>\mathrm{P}_{\mathrm{SD}}$ the fluidl 22 penetrates during the contact stage. In the fakir state, fol 23 having a rebound as outcome of the drop impact is neces 124 sary that the liquid lamella is stretched enough to have 25 sufficient energy at the end of the recoiling phase, thus 26 promoting the drop detachment from the surface, i.e. it is 27 necessary to have enough impact kinetic energy (the ki128 netic energy of the impinging droplet has to be larget 29 than the surface energy dissipated during the retraction 30

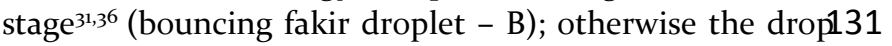
does not rebound (non-bouncing fakir state - NB). When132 the liquid meniscus penetrates the surface topology, thel33 partially impaled state occurs: at low impact velocity a134 partially penetrated bouncing droplet state (PPB) occurs 135 instead at higher drop impact velocity, i.e. for a given crit136 ical velocity $U_{c, p}$, the so-called second non-bouncing 37 droplet $(2 \mathrm{NB})$ state $^{32}$ occurs.

The main problem is that there is still an open debate on139 the criteria for impalement, since, if it is clear that im 140 palement will appear when the anti-wetting pressure $\mathrm{P}_{\mathrm{C}}$ is 41 lower than a pressure linked to the impact dynamics, i.e142 $\mathrm{P}_{\mathrm{EWH}}, \mathrm{P}_{\mathrm{GL}}$ or $\mathrm{P}_{\mathrm{SD}}$, the actual threshold values are still un 143 known. Maitra et al.47 suggested that $\mathrm{P}_{\mathrm{GL}}>8$ o $\mathrm{P}_{\mathrm{C}}$ shouldll4 be used as an impalement criterion, which impedes the145 complete rebound. From this expression the critical We146 ber number above which a complete rebound cannot oc 147 cur can be evaluated: $W e_{\text {cr,imp }}=18.2 \mathrm{R}^{1 / 2} \mu_{\mathrm{g}}{ }^{2 / 7} \mathrm{Pl}^{-1 / 7} \sigma 148$ ${ }^{1 / 7}\left(\cos \theta_{\mathrm{A}}\right)^{9 / 14} \mathrm{r}_{\mathrm{p}}{ }^{-9 / 14}$. The smaller the cavity size, the higher 49 must be the impact velocity above which also Cassie-to150 Wenzel transition (CWT) ${ }^{22,37}$ will occur. This is in qualita151 tive agreement with the different output we observed at52 high We on surfaces with different morphologies: S and S153 samples have nanoscale cavities on their surfaces, hence a154 $U_{c, p}$ higher $\left(\mathrm{We}\left(U_{c, p}\right)>620\right)$ than the maximum $U$ investi-155 gated in these experiments. Instead, LAU and FAS surfac-156 es displayed only sub-micrometric voids which originated157 a smaller $U_{c, p}$ and therefore the CWT can be observed a\&58 We 550 for LAU and We 200 for FAS. However, it is very 159 difficult to assess the critical Weber number for surfaces 60 having a stochastic roughness, such as those used in the161 present work. $\mathrm{We}_{\mathrm{cr}, \mathrm{imp}}$ and $\mathrm{P}_{\mathrm{C}}$ are hard to determine duel62 the length scale parameter for the surface cavities. More 163 over, Quan and Zhang ${ }^{38}$ demonstrated how the initial and164 operating conditions, including the microstructured su-165 perhydrophobic surfaces geometrical shapes will signifi-166 cantly influence the bouncing ability of an impinging 67 droplet on textured surfaces.
Because the drop mobility is related to a sort of "dynamic superamphiphobicity", defined as the critical wetting value under which a complete drop rebound is observed, the critical impact velocity for having a dynamical amphiphobic surface is increasing with the surface tension, i.e., for the same advancing contact angles, a low surface tension fluid will have a lower threshold for impalement. Hence for a given impact velocity, a drop tends to deposit rather than to rebound when a lower surface tension fluid is involved. It is also important to stress that another important dimensionless number, the Ohnesorge number, i.e. the viscous dissipation, may influence the drop rebound. For water, the Ohnesorge number is about 0.0024 , while for hexadecane is 7 times higher $\left(\mathrm{Oh}_{\mathrm{Hex}} \approx 0.0177\right)$, therefore, the viscous dissipation prevents the liquid to rise back ${ }^{41}$ from the partial penetration to a Cassie-Baxter regime. Since for our experiments the drop rebound is not possible to be achieved using hexadecane, the single effect of viscosity cannot be estimated. The rebound may therefore happen for a given impact velocity range $U_{r, \min }<$ $\mathrm{U}<\mathrm{U}_{\mathrm{r}, \max }{ }^{31,39,40}$.

Finally in the present literature, the "chemistry" of the surface and of the liquid has never been considered a crucial factor for determining the CWT. However, it becomes clear that also the chemistry of the surface and the physico-chemical interactions with the liquid drops play an important role in determining $\mathrm{We}_{\mathrm{cr}, \mathrm{mp}}$. For water drops with $\mathrm{We}=150 \div 360$, different outputs are observed for LAU and FAS surfaces notwithstanding their identical morphology (see Table 1 and Figures 2 and 8) and wettability (see Figure 1). The difference between these surfaces must lie in their chemical composition, as LAU is functionalized with non-polar alkyl chains while FAS exposes polar fluorinated groups. Murase and Fujibayashi ${ }^{42}$ demonstrated that water forms hydrogen bonds with such fluorinated moieties on hydrophobic surfaces. Therefore, we may consider that these interactions cause kinetic energy dissipation in the drop. Nakajima et al.43 calculated that this dissipation depends on the contact area between the drop and the surface. At $\mathrm{We}<150$, drop spreading is limited, thus water-surface contact area is small and the interaction negligible. Increasing impact speed, drop spreading and contact area become larger, therefore hydrogen bonds start to play a role causing dissipation and hindering rebound. When $\mathrm{We}>500$, water drops penetrate the terrace-like morphology of both LAU and FAS samples (e.g. partial rebound), therefore the role of chemistry is no longer relevant. Instead, for hexadecane drops, no influence of the surface chemistry can be recognized: the very low surface tension makes more probable to either splash at high We or deposit at low We, when the kinetic energy is insufficient to break the drop. Only a small influence of the surface structure is observed, causing the splash-deposition transition to shift to lower Weber values for the S and SI samples with a 
flower-like surface morphology (Table 1). This is the firs2223 time that this influence of chemistry on the drop impact224 behavior on textured surfaces is reported. However, othę25 explanation can be evoked as well, e.g. a more inhomoge226 neous grafting of FAS chains on unexposed parts of the227 surface topology with respect to LAU molecules. Static oæ228 quasi-static wetting measurements might not highligh229 such differences in surface chemical composition, while230 impinging drops could "touch" these areas and cause re231 tention of the drop. As if a wettability gradient along the 232 surface asperities is formed, that causes a different drop233 surface interaction. Future work will extend the comprehension of such phenomena, possibly adding molecula234 dynamics modeling of the interactions between the $\operatorname{sur}_{235}$ face and the drop.

\section{CONCLUSIONS}

The normal impact of water and hexadecane liquid drops 238 onto dry, rigid surfaces with different wettabilities has 40 been studied experimentally using a high-speed camera. The results highlighted that it is not possible to easily cor241 relate contact angles (receding, advancing and hysteresis) and drop impact dynamics of low and high surface ten 243 sion liquids on different surfaces. The Cassie-to-Wenze 244 transition can be observed even on statically repellen 245 surfaces. In order to explain the observed phenomena 246 physical and chemical characteristics of both the liquich247 drops and the surface have to be taken into account. Sur-

face morphology is crucial in defining the critical velocity248 over which impalement occurs: the smaller the surface 249 cavities, the higher $U_{c r, i m p}$. Also, surface chemistry as hy-250 drogen bonding between surface functional groups an $\$ 51$ molecules in the liquid phase, can lower $\mathrm{U}_{\mathrm{cr}, \mathrm{imp}}$ and favoz 52 impalement, as the wettability gradient along the surface 253 asperities is relevant in determining the drop impact be 254 havior. As far as the liquid properties are concerned, ir 255 agreement with Butt 39 , with increasing viscosity and lowe 256 fluid surface tension the CWT shifts to smaller Webeh 257 numbers. In the case of hexadecane drops, the CWT 259 threshold is so low that no rebound has been observed 260 even if the contact angles are well above the expected261 critical values obtained from previous works focusing on262 water drops. The effect of energy dissipation for high vis 263 cous fluids is therefore important when the liquid retreats 264 from the texture ${ }^{44,45}$. Finally, it is clear that, at the mo 265 ment, there is still a lack of an agreed general and quanti 266 tative evaluation of the impalement criteria after a drop268 impact. For example, the proposed thresholds in litera-269 ture are not yet able to properly describe the results ob-270 tained using oils on amphiphobic surfaces.

271

272

A direct consequence of the study is linked to the numer-273 ical simulations of drop impacts onto rigid and dry surz 274 faces. They consider the advancing and receding contac2 275 angles and surface tension in order to represent the im- pact outcomes ${ }^{46}$. A direct and important consequence of this study is that all the numerical simulations of drop impact onto solid, dry surfaces will never be able to capture the final outcome of the impact for all the possible fluids, if the surface topology and chemistry are not properly considered. Static or quasi-static wetting measurements might not highlight such differences in surface chemical composition. Furthermore, the present results emphasize how an accurate design of the surface properties must be pursued in the future research towards dynamically amphiphobic surfaces.

\section{AUTHOR INFORMATION}

\section{Corresponding Author}

*E-mail:m.marengo@brighton.ac.uk

\section{Author Contributions}

The manuscript was written through contributions of all authors. All authors have given approval to the final version of the manuscript.

\section{ACKNOWLEDGMENTS}

The authors acknowledge the European Cooperation in Science and Technology - MPNS COST Action MP11o6 "Smart and green interfaces - from single bubbles and drops to industrial, environmental and biomedical applications" led by Prof. T. Karapantsios.

\section{REFERENCES}

1. Marengo, M.; Antonini, C.; Roisman, I. V.; Tropea, C. Drop collisions with simple and complex surfaces. Curr. Opin. Colloid Interface Sci. 2011, 16, 292-302.

2. Bertola, V.; Wang, M. Dynamic contact angle of dilute polymer solution drops impacting on a hydrophobic surface. Colloids Surf., A 2015, 481, 600-608.

3. Milionis, A.; Krishnan, K. G.; Loth, E. Hemolymph drop impact outcomes on surfaces with varying wettability. App. Surf. Sci. 2015, 345, 36-43.

4. Malavasi, I.; Bernagozzi, I.; Antonini, C.; Marengo, M. Towards a standard protocol for assessing durability of superhydrophobic surfaces. Surface Innovations 2014, 3, 49-6o.

5. Feng, X. J.; Jiang, L. Design and Creation of Superwetting/Antiwetting Surfaces. Adv. Mater. 20o6, 18, 30633078.

6. Quéré, D. Non-sticking drops. Rep. Prog. Phys. 2005, 68, 2495-2532.

7. Shirtcliffe, S. N. J.; McHale, G.; Atherton, S.; Newton, M. I. An introduction to superhydrophobicity. Adv. Colloid Interface Sci. 2010, 161, 124-138.

8. Jiang, J. Y.; Xu, J. L.; Liu, Z.H.; Deng, L.; Sun, B.; Liu, S. D.; Wang, L.; Liu, H. Y. Preparation, corrosion resistance and hemocompatibility of the superhydrophobic $\mathrm{TiO}_{2}$ coatings on biomedical Ti-6Al-4V alloys. App.Surf. Sci. 2015, 347, 591-595.

Crawford, R. J.; Ivanova, E. P. Biological Interactions with Superhydrophobic Surfaces. In Superhydrophobic Surfaces; Elsevier: 2015; pp 151-160. 
10. Gogolides, E.; Ellinas, K.; Tserepi, A. Hierarchical micr336 and nano structured, hydrophilic, superhydrophobic anB37 superoleophobic surfaces incorporated in microfluidics338 microarrays and lab on chip microsystems. Microelectron. Eng339 2015, 132, 135-155.

11. Zhang, F. Z.; Zhao, L. L.; Chen, H. Y.; Xu, S. L.; Evans, D341 G.; Duan, X. Corrosion resistance of superhydrophobic layere B42 double hydroxide films on aluminum. Angew. Chem. Int. EdB43 2008, 47, 2500-2503.

344

12. Lee, C. Y.; Kim, C. J. Underwater restoration and retentior345 of gases on superhydrophobic surfaces for drag reduction346 Phys. Rev. Lett. 2011, 106, 14502-14506.

347

13. Antonini, C.; Innocenti, M.; Horn, T.; Marengo, M.348 Amirfazli, A. Understanding the effect of superhydrophobi349 coatings on energy reduction in anti-icing systems. Cold Reg350 Sci. Technol. 2011, 67, 58-67.

351

14. Genzer, J.; Efimenko, K. Recent developments i1ß52 superhydrophobic surfaces and their relevance to marine353 fouling: a review. Biofouling 2006, 22, 339-360.

354

15. Yuan, Y.; Lee, T.R. Contact Angle and Wetting Properties355 In Surface Science Techniques; Bracco, G., Holst, B., Eds.356 Springer Series in Surface Sciences 51; Springer: 2013; pp 3-34. 357 16. Cavalli, A.; Mugele, F. Superamphiphobic Surfaces. Irß58 Droplet Wetting and Evaporation; Brutin, D. Eds.; From Pure t\$59 Complex Fluids; Elsevier, Academic Press: Aix-Marseill360 University, France, 2015; pp 57-69.

361

17. Mou, C. Y.; Yuan, W. L.; Shih, C. H. Preparation anß62 characterization of ultra-thin amphiphobic coatings on silicor363 wafers. Thin Solid Films 2013, 423, 202-207.

364

18. Tsekov, R.; Borissov, D.; Karakashev, S. I. Wetting65 dynamics on lyophilic solid surfaces patterned by lyophobi366 islands. Colloids Surf., A 2013, 77-80.

367

19. Wang, H.; Gao, D.; Meng, Y.; Wang, H.; Wang, E.; Zhu, Y368 Corrosion-resistance, robust and wear-durable highl369 amphiphobic polymer based composite coating via a simple370 spraying approach. Prog. Org. Coat. 2015, 82, 74-80. 371 2o. Chua, Z.; Seeger, S. Superamphiphobic surfaces. Chem372 Soc. Rev. 2014, 43, 2784-2798.

373

21. Antonini, C.; Villa, F.; Bernagozzi, I.; Amirfazli, A.374 Marengo, M. Drop Rebound after Impact: The Role of the375 Receding Contact Angle. Langmuir 2013, 29, 16045-1605o. 376 22. Maitra, T.; Tiwari, M. K.; Antonini, C.; Schoch, P.; Jung, S.377 Eberle, P.; Poulikakos, D. On the Nanoengineering oB78 Superhydrophobic and Impalement Resistant Surface Textures79 below the Freezing Temperature. Nano Lett. 2014, 14, 172-182. 380 23. Roisman, I. V.; Lembach, A.; Tropea, C. Drop splashing81 induced by target roughness and porosity: The size plays no382 role. Adv. Colloid. Interface Sci. 2015, 222, 615-621.

24. Raimondo, M.; Blosi, M.; Caldarelli, A.; Guarini, G.384 Veronesi, F. Wetting behavior and remarkable durability oB85 amphiphobic aluminum. Chem. Eng. J. 2014, 258, 101-109. 386 25. Yang, S.; Qiu, R.; Song, H.; Wang, P.; Shi,Z.; Wang,Y387 Slippery liquid-infused porous surface based or388 perfluorinatedlubricant/iron tetradecanoate: Preparation an\$89 corrosion protectionapplication. App.Surf. Sci. 2015, 328, 491390 500.

391

26. Charpentier, T. V. J.; Neville, A.; Baudin, S.; Smith, M. J.392 Euvrard, M.; Bell, A.; Wang, C.; Barker, R. Liquid infuseB93 porous surfaces for mineral fouling mitigation. J. Colloiß94 Interface Sci. 2015, 444, 81-86.
27. Bernagozzi, I.; Antonini, C.; Villa, F.; Marengo, M. Fabricating superhydrophobic aluminum: an optimized onestep wet synthesis using fluoroalkyl silane. Colloids Surf., A 2014, 441, 919-924.

28. Geometric Product Specifications (GPS) - Surface texture: Areal - Part 2: Terms, definitions and surface texture parameters. ISO 25178, April o1, 2012.

29. Antonini, C.; Amirfazli, A.; Marengo, M. Drop impact and wettability: from hydrophilic to superhydrophobic surfaces. Phys. Fluids. 2012, 24, 102104-102113.

30. Bartolo, D.; Josserand, C.; Bonn, D. Singular Jets and Bubbles in Drop Impact. PRL 2006, 96, 124501_1-4.

31. Bartolo, D.; Bouamrirene, F.; Verneuil, É.; Buguin, A.; Silberzan, P.; Moulinet, S. Bouncing or sticky droplets: Impalement transitions on superhydrophobic micropatterned surfaces. Europhys. Lett. 2006, 74, 299-305.

32. Kwon, D. H.; Lee, S. J. Impact and wetting behaviors of impinging microdroplets on superhydrophobic textured surfaces. Appl. Phys. Lett. 2012, 100, 171601_1-4

33. Deng, T.; Varanasi, K. K.; Hsu, H.; Bhate, N.; Keimel, C.; Stein, J.; Blohm, M. Nonwetting of impinging droplets on textured surfaces. Appl. Phys. Lett. 2009, 94, 133109_1-3.

34. Moulinet, S.; Bartolo, D. Life and death of a fakir droplet: Impalement transitions on superhydrophobic surfaces. Eur. Phys. J. E 2007, 24, 251-26o.

35. Mandre, S.; Mani, M.; Brenner; M.P. Precursors to Splashing of Liquid Droplets on a Solid Surface. PRL 2009, 102, 134502_1-4.

36. Reyssat, M.; Pépin, A.; Marty, F.; Chen, Y.; Quéré, D. Bouncing transitions on microtextured materials. Europhys. Lett. 2006, 74, 306-312.

37. Antonini, C.; Lee. J. B.; Irvine, S.; Derome, D.; Tiwari, M. K.; Carmeliet, J.; Poulikakos, D. Unraveling wetting transition through surface textures with X-rays: Liquid meniscus penetration phenomena. Sci. Rep. 2014, 4:4055, 1-6.

38. Quan, Y.; Zhang, L.Z. Numerical and Analytical Study of The Impinging and Bouncing Phenomena of Droplets on Superhydrophobic Surfaces with Microtextured Structures. Langmuir 2014, 30, 11640-11649.

39. Deng, X.; Schellenberger, F.; Papadopoulos, P.; Vollmer, D.; Butt, H. J. Liquid Drops Impacting Superamphiphobic Coatings. Langmuir 2013, 29, 7847-7856.

40. Schutzius, T. M.; Jung, S.; Maitra, T.; Eberle, P.; Antonini, C.; Stamatopoulos, C.; Poulikakos, D. Physics of Icing and Rational Design of Surfaces with Extraordinary Icephobicity. Langmuir 2015, 31, 4807-4821.

41. Extrand, C. W. Forces, pressures and energies associated with liquid rising in nonuniform capillary tubes. J. Colloid Interface Sci. 2015, 450, 135-140.

42. Murase, H.; Fujibayashi, T. Characterization of molecular interfaces in hydrophobic systems. Prog. Org. Coat. 1997, 31, 97-104.

43. Nakajima, A.; Miyamoto, T.; Sakai, M.; Isobe, T.; Matsushita, S. Comparative study of the impact and sliding behavior of water droplets on two different hydrophobic silane coatings. App.Surf. Sci. 2014, 292, 990-996.

44. Lee, J. B.; Lee, S. H. Dynamic Wetting and Spreading Characteristics of a Liquid Droplet Impinging on Hydrophobic Textured Surfaces. Langmuir 2o11, 27, 6565-6573.

45. Hyvaluoma, J.; Timonen, J. Impact states and energy dissipation in bouncing and non-bouncing droplets. J. Stat. Mech. 2009, Po6o10+10. 

during the drop spreading: standard models and a nove\#04 wetting force model. Adv. Colloid. Interface Sci. 2014, 212, 1-20. 405

47. Maitra, T.; Tiwari, M.K.; Antonini, C.; Schoch, P.; Jung, S.; Eberle, P.; Poulikakos, D. Correction to On the Nanoengineering of Superhydrophobic and Impalement Resistant Surface Textures below the Freezing, Temperature, Nano Lett. 2014, 14 (1), 172-182. DOI: 10.1021/nl4037092 
1 TOC Graphic

2

3
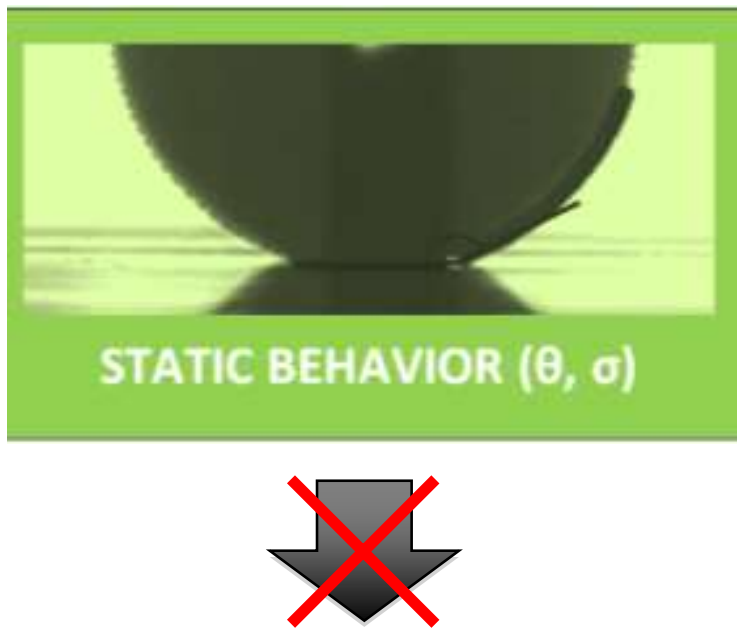

DYNAMICAL BEHAVIOR

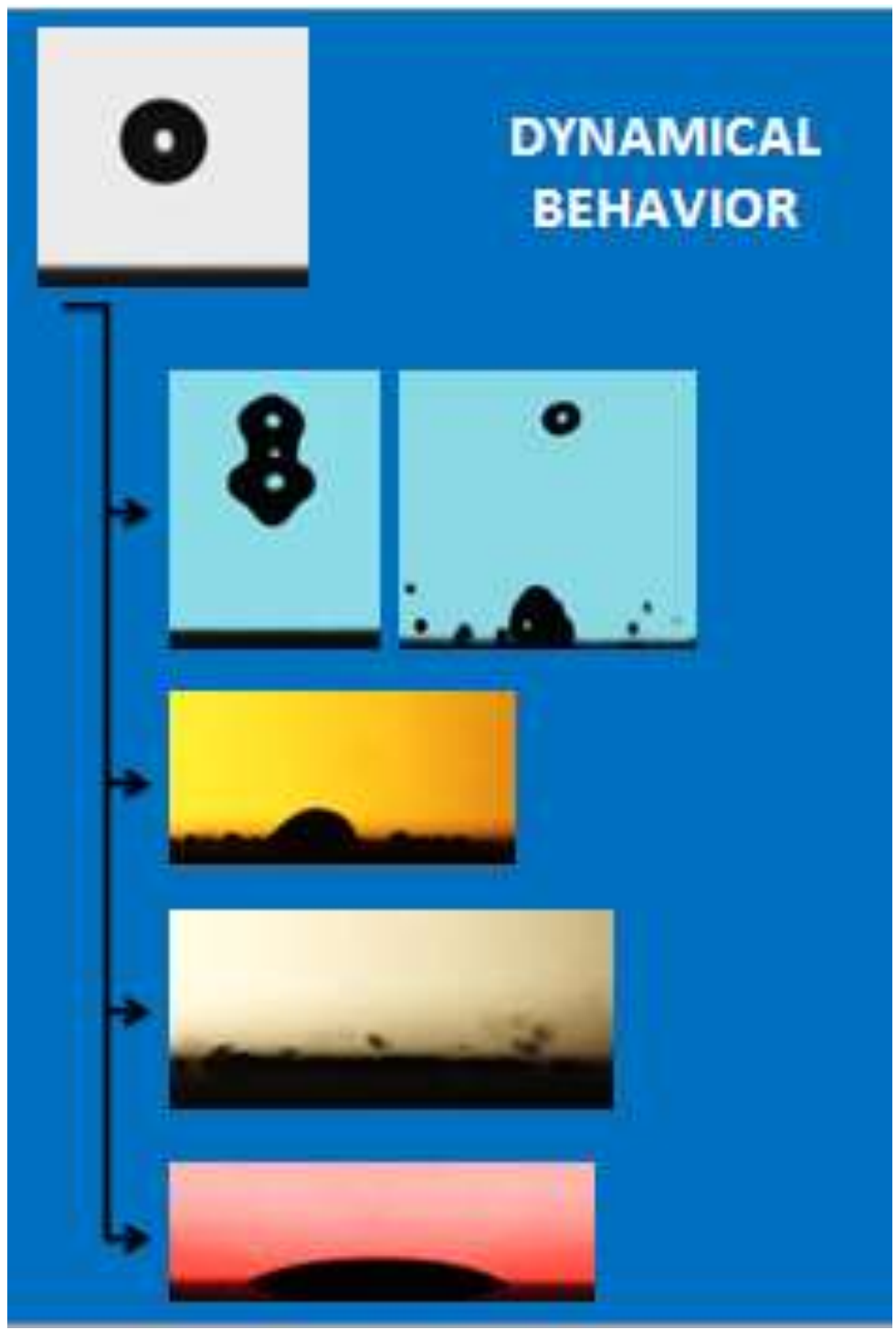

